\title{
INTRODUCTION: MEASURING HUMAN RESOURCE EFFECTIVENESS AND IMPACT
}

\author{
Arthur K. Yeung, Guest Editor
}

This special issue represents the collective wisdom of approximately 100 participants who attended the "HR Measurement Symposium" in late 1995. Sponsored by the California Strategic Human Resource Partnership, a human resources (HR) consortium consisting of top HR executives of 30 leading companies in Northern California, the symposium was designed to share and shape emerging thinking in the area of HR measurement. With Dave Ulrich and I acting as cochairs of the symposium, four academic thought leaders and six corporate speakers were invited to present their ideas and work in the one-and-a-half day conference. The presenters in the symposium were:

- AT\&T

- Champion

Tapas Sen International

- Cornell University

Steve Gardiner

- Eastman Kodak

John Boudreau

- Merck

Bob Berman

- Motorola

Jim Higgins

- Saratoga Institute

Dick Wintermantel

- Sears

Jac Fitz-enz

Rick Quinn

- Stanford University

- University

Jeffrey Pfeffer

Dave Ulrich

of Michigan

In reflecting on the key learnings of the symposium, there are five key insights that derive from the presentations and discussion:

\section{Traditional HR Measures Are Inadequate and Perhaps Misleading}

While traditional HR measures are easy to develop and convenient for collecting data, they are not very useful for two reasons. First, they tend to reward and reinforce HR professionals for activities (e.g., number of training programs, number of new hires), not business impact. Second, they provide historical/lag data (e.g., turnover, absenteeism, employee morale), not predictive information on which line executives can act. As a result, there is a general consensus that traditional HR measures need to be modified and/or discarded.

\section{New HR Measures Need to Be Developed within a Framework}

If HR measures are intended to measure business impact and to stimulate change for business improvement, a fundamental question is: How can HR add value to business success? Unless HR professionals are crystal clear about how and why they can impact business performance (Boudreau \& Ramstad), it is hard to develop the appropriate HR measures to demonstrate their value added and to engage other managers to behave based on those measures. In the symposium it was found that many companies such as AT\&T, Sears, and Eastman Kodak have begun to build their HR measures based on the balanced scorecard principle (Yeung \& Berman; Ulrich). Other 
companies such as Motorola have developed their HR measures based on their HR mission (Wintermantel \& Mattimore). Regardless of the framework being used, however, the key criteria remain the same: (1) the framework must be credible, both intellectually and empirically; and (2) it needs to be widely accepted by both HR and line communities.

\section{HR Measures Are Not Only for HR Professionals}

As the quality of people management always depends on the leadership process of line managers, new HR measures should also hold line managers, in addition to HR professionals, accountable. While HR professionals are responsible for designing strategically aligned HR practices, the ultimate responsibility of people management resides on managers. Many companies, such as Motorola, GE, AT\&T, and Sears, have explicitly assessed and rewarded line managers based on their effectiveness in people management (Ulrich).

\section{Utilization of HR Measures Is of Ultimate Importance}

While many companies have devoted extensive time to developing the "right" measures and to collecting quantities of data on employee satisfaction, turnover, absenteeism, customer satisfaction, productivity, etc., they are weak in utilizing the data in two ways. First, companies do not follow through an action learning cycle that includes measures development, data capturing, feedback/communication, changing activities/practices, and business improvement. Very often, data that are collected are neither widely shared within the organization, nor are they broken down to the appropriate level for action planning. As a result, data lead to little action, impact, and consequence. Naturally, employees become frustrated and are not interested in participating in future data collection efforts. Second, companies are not able to integrate and combine different databases in a meaningful way (Boudreau \& Ramstad). For instance, companies often do not assess the relationships between employee satisfaction, customer satisfaction, and financial outcomes. As a result, they have no idea which issues are critical to their employee performance and which are not.

\section{Measurement Is Subject to Politics}

As measurement affects performance ratings, prestige, power, and resource allocation of its users (at both functional and individual levels), it is not simply a technical or rational concern. Companies should expect strong resistance and influence from related stakeholders (e.g., HR professionals, line managers, employees, unions, customers) in developing measurement that advances the stakeholder's own interests. Jeffrey Pfeffer in this special issue argues that measurement is disadvantageous for HR professionals, as it is a game that accounting and finance people can play much better than HR professionals.

While not all presenters in the symposium were able to prepare an article for this special issue, the five articles included here represent a wide spectrum of ideas discussed in the conference.

- Dave Ulrich's article provides an excellent overview on various approaches that companies can use to measure their HR effectiveness and impact.

- Using Eastman Kodak as a case study, Yeung and Berman illustrate how a company develops its HR measures based on the balanced scorecard principle.

- Wintermantel and Mattimore's article ties the evolution of HR measures to the changing HR mission.

- Drawing from the historical development of financial and marketing measures, Boudreau and Ramstad suggest three specific ways to articulate and develop the appropriate HR measures.

- Last but not least, Pfeffer's article offers a unique perspective in sensitizing the readers to the pitfalls involved in HR measurement.

Finally, I am pleased to have this opportunity to acknowledge the sponsorship of the 
California Strategic Human Resource Partnership in organizing the "HR Measurement Symposium," the intellectual leadership of Dave Ulrich in designing the symposium, and the generosity of Quantum Corporation in hosting the event. Without their sponsorship and contribution, this special issue could not have become a reality. 
